Research Article

\title{
How Does Knowledge Coupling Affect Firm's Incremental Innovation? The Moderating Effects of Government Support Policies
}

\author{
Zhou Huiping $(\mathbb{D})$ and Yang Yuxin \\ School of Business Administration, Guangdong University of Finance and Economics, Guangzhou 510320, China \\ Correspondence should be addressed to Zhou Huiping; zhouhuiping0807@163.com
}

Received 17 June 2021; Accepted 22 September 2021; Published 10 November 2021

Academic Editor: Haoran Zhang

Copyright (c) 2021 Zhou Huiping and Yang Yuxin. This is an open access article distributed under the Creative Commons Attribution License, which permits unrestricted use, distribution, and reproduction in any medium, provided the original work is properly cited.

\begin{abstract}
Acquiring and combining different knowledge elements across organizational boundaries has become an important strategy for firms' innovation outcomes. Based on the theory of resource orchestration, this paper divides knowledge coupling into two dimensions: complementary knowledge coupling and substitutable knowledge coupling. Then, this study aims to explore the different impacts of knowledge coupling types on firm's incremental innovation and verify the moderating role of government support policies in this relationship. Based on the survey of 279 high-tech enterprises from China, our analysis results indicate the following. (1) Complementary knowledge coupling has an inverted U-shaped impact on firm's incremental innovation, while substitutable knowledge coupling has a positive influence on incremental innovation. (2) The fitness between government support policies and knowledge coupling types can promote the result of firm's incremental innovation: when firms adopt complementary knowledge coupling strategies, finance and taxation support policies are more conducive to firm's incremental innovation; when enterprises use substitutable knowledge coupling strategies, innovative environment support policies are better for the promotion of firm's incremental innovation. The research results provide a theoretical basis for firms to select appropriate government support strategies to exert the effects of innovation based on characteristics of internal and external knowledge resources.
\end{abstract}

\section{Introduction}

In the era of digital economy, enterprises need to combine heterogeneous knowledge resources to achieve their innovation targets. For example, Nike and Apple jointly launched the Nike + iPod brand. Internet companies such as Google and Baidu have crossed technology boundaries to produce cars. The knowledge base view emphasizes that the ability of a firm to create, accumulate, and apply knowledge is vital for sustaining competitive advantages [1]. A firm's knowledge base is characterized by set of knowledge elements it possesses and the relationships it has forged between knowledge domains to which these elements belong [2]. Thus, the coupling between knowledge elements in different knowledge domains is crucial to knowledge creation and firms' innovation.
The concept of coupling originated in physics. Yayavaram and Ahuja first used knowledge coupling to describe the structure by which different knowledge elements are coupled together or isolated from each other [3]. However, they have not distinguished the different types of knowledge coupling, which highlights the need for identifying the relationship between different knowledge coupling types and firms' innovation. Furthermore, although scholars have reached a certain consensus on the positive role of knowledge element combination on firms' innovation outcomes [3,4], some studies state that whether a particular type of knowledge coupling is beneficial or detrimental may depend on the innovation contexts by which the firm operates [5]. Resource arrangement theory emphasizes the process that enterprises realize the combination of knowledge from partners to stimulate utility through resource- 
focused actions $[6,7]$. Therefore, it is key for organizations to combine different knowledge elements across technologies to realize their innovation performance. In addition, existing research mainly focused on the impacts of knowledge elements coupling on enterprises radical innovation activities [8]. With the continuous integration of digital technology, "fragmented" production constitutes a new production mode to foster strengths and expand profits [9]. Therefore, the emergence of industrial division of labor provides an opportunity for enterprises to seek incremental innovation through continuous improvement of original products [10]. In this context, how does the interaction and coupling of knowledge elements in different knowledge domain affect firms' incremental innovation?

Government support policies are important institutional factors for enterprises' innovation, especially in the context of China's economic transformation, where the government controls lots of resources. Existing literature mainly emphasizes the effectiveness of government support as a catalyst for enterprises' innovation from government fiscal subsidies and tax incentives [11]. However, scholars have not verified the fitness between government support policies and knowledge management activities to affect firms' innovation outcomes. In fact, it is of great practical value and theoretical significance to follow the synergistic effects of government policy on enterprises' innovation.

Thus, this paper aims to explore the fitness influences of knowledge coupling types and government support policies on enterprises' incremental innovation from the perspective of resource arrangement theory. Firstly, from the perspective of resource arrangement theory and the view of relational properties of knowledge elements, we aim to verify the differentiated effects of complementary knowledge coupling and substitutable knowledge coupling on enterprises' incremental innovation. Existing literature ignored the classification and exploration of different knowledge coupling types, and scholars have not reached a consensus on different types of knowledge element coupling affecting enterprises innovation $[5,12,13]$. This paper provides a new insight for the cross study of knowledge management and innovation strategy.

Secondly, this paper tries to find the fitness relationship between knowledge coupling types and government supporting policies by discussing the moderating effect of government supporting policies between knowledge coupling and incremental innovation. Current studies have not classified the positive impacts of government support policies on firms' innovation from the perspective of synergy. This paper proposes a fitness model between knowledge coupling types and government support policies, which provides a new perspective for government policies and firms' innovation research.

\section{Theory and Hypothesis}

As prior literature has not identified the relationship between different knowledge coupling types and firms' innovation. This study employs the resource arrangement theory as a theoretical frame for examining how knowledge coupling affects firm's incremental innovation and the moderating role of government support policies in this relationship.

2.1. Classification of Knowledge Coupling. The coupling decision is driven by firms' market, competitors' actions, external partners' knowledge, and social environment [14]. Innovation is a process in which a large number of heterogeneous knowledge elements interact and combine to generate new knowledge [15]. Therefore, it is vital to distinguish different types of knowledge coupling strategy for firms' innovation. Based on the concepts of complementary knowledge and substitutable knowledge, we divide the coupling decision of knowledge elements into two structures: complementary knowledge coupling and substitutable knowledge coupling $[16,17]$.

2.1.1. Complementary Knowledge Coupling. The concept of "complementarity" originated in economics field. Teece [18] first defined the complementarity of resources among different subjects. Complementary knowledge creates large number of learning opportunities and innovation potential through reorganization of technologies and skills [19]. The value or effects of two knowledge elements with complementary relationship are greater than the knowledge element alone. We define complementary knowledge coupling as a process of firms to combine two knowledge elements from different knowledge domains to produce new knowledge elements.

2.1.2. Substitutable Knowledge Coupling. Substitutable knowledge refers to the highly redundant knowledge elements with similar characteristics or skills [20]. Since redundancy means the overlapping between knowledge elements, it is easier for substitutable knowledge to be transferred. Therefore, substitutable knowledge is more conducive to the improvement of products or technologies. In this paper, substitutable knowledge coupling is defined as the process of enterprises to combine two knowledge elements with similar nature to constantly update its knowledge base.

\subsection{The Impacts of Knowledge Coupling on Firms' Incremental} Innovation. Acquiring and making use of external knowledge sources to create new knowledge is vital for firms to sustain competitive advantage. In this part, we aim to explore the different impacts of knowledge coupling types on firm's incremental innovation.

\subsubsection{The Impact of Complementary Knowledge Coupling on} Firms' Incremental Innovation. Incremental innovation is an innovation process in which a firm gradually improves existing products, expands existing market, and improves its internal operation to meet existing customers and market demands [21]. Firstly, resource arrangement theory 
emphasizes the effective combination of internal and external resources to promote resource appreciation, thus affecting the growth of enterprises [6]. The new knowledge acquired in different knowledge domains through searching process can be reorganized with firms' existing knowledge base, which is conducive to the elimination of old knowledge for continuous improvement of their products or services. Secondly, the coupling of complementary knowledge elements can also expand existing technologies and markets. For example, some scholars point out that the combination of heterogeneous knowledge elements not only is conducive to generating new ideas but also can deepen enterprises' cognition of knowledge to improve products or service to meet demands of existing market [22]. Thirdly, the interaction of heterogeneous knowledge elements also provides new ideas and motivations to restructure enterprises internal knowledge management processes, which can promote their internal operating processes through optimizing resource allocation and product design, to meet the needs of market and customers.

However, with the deepening of the coupling between complementary knowledge elements, it will have negative impacts on firms' incremental innovation. Although the coupling of knowledge elements in different knowledge domains can create new knowledge or technology, it will also increase the cost of knowledge management. First, searching for knowledge in different technical fields will be faced with highly uncertain factors such as lack of experience and ability, which will increase the probability of wrong decisions of enterprises [22]. Second, when the interaction of knowledge elements from different technical domains strengthens beyond a certain point, the costs and risks are associated with its integration can increase dramatically [23]. Consequently, it is reasonable to expect that the benefits deriving from complementary knowledge coupling may be exceeded by the cost. Third, when enterprises expand their knowledge searching activities to new technical fields, they need to invest a lot of cost and energy, which will disperse their research and development activities and is not conducive to the improvement of enterprises' incremental innovation ability.

Thus, this paper proposes the following hypothesis:

H1a: the complementary knowledge coupling has an inverted U-shaped effects on firms' incremental innovation.

\subsubsection{The Impact of Substitutable Knowledge Coupling on} Firms' Incremental Innovation. The influence of substitutable knowledge coupling on firms' incremental innovation is realized by reorganizing the knowledge elements of the same or similar fields, which can help to update enterprises' knowledge base and improve the efficiency of knowledge reorganization to improve their products or technologies. First of all, when the coupling degree of knowledge elements in the same field is high, firms can better understand their existing knowledge system to enhance the professional degree of technical knowledge [17], to integrate key resources and apply them to the production of products or service processes, and to meet the needs of existing market or customers. Secondly, the interaction of homogenous knowledge elements can help enterprises develop new knowledge combinations or new problem-solving methods, to avoid the "familiarity trap" in a certain extent [24]. The reorganization of substitutable elements also provides new ideas for solving problems in the production or development process, which can improve the performance of products or service. Finally, the recombination of specialized knowledge in the same or similar fields can also enhance enterprises' core competence, and the knowledge coupling process can realize the iteration of new and old knowledge and the dynamic accumulation of knowledge base, to extract more effective knowledge, which can shorten the production cycle of products and improve the operating efficiency of enterprises [18]. Based on this, this paper puts forward the following hypothesis:

H1b: substitutable knowledge coupling is positively correlated with firms' incremental innovation.

\subsection{The Moderating Effects of Government Support Policies.} Under the background of digital economy, government plays a key role in maintaining the normal order of market. However, "how" and "how much" government supports innovation are still controversial. In addition, existing studies emphasize the effectiveness of government support as a catalyst for firms innovation, but prior literature has paid little attention on how different government support policies affect firms' innovation outcomes [11]. Therefore, we divide government support policies as two types: fiscal and tax support and innovative environment support [25]. Fiscal and tax support mainly involves tax incentives, financial subsidies, government procurement, and other direct economic means. The innovative environment support includes indirect system environment of various economic and financial services, intellectual property protection, talent incentive policies, and so on.

As one of important tools to promote enterprises' independent innovation ability, government's fiscal and tax policies play an important role in China's economic and social development, which have also aroused the reflection of theoretical and practical circles. On the one hand, the government supports $\mathrm{R} \& \mathrm{D}$ activities of enterprises by means of tax exemptions and fiscal subsidies, which help to supplement their innovation resources and can reduce the uncertainty and risk diversification of innovation activities, to promote their R\&D and innovation activities [26]. At the same time, government subsidies also play a positive role in sending signals to outside world, which helps firms acquire heterogeneous knowledge resources from external partners and provides favorable support to combine knowledge elements to promote innovation performance [26].

On the other hand, scholars propose that government's fiscal and tax support policies may produce "crowding-out effect" on firms' innovation activities [27]. Due to the public property right of government's fiscal and tax policies and the high risk and serious information asymmetry of innovation, it is difficult for the government to effectively supervise the use of fiscal and tax subsidies. Therefore, when some enterprises own 
rich resources and have obtained government subsidies, they will aggravate the problem of original resource redundancy and reduce their willingness to update knowledge resources, which is not conducive to the improvement of existing technologies and products.

Therefore, we propose the following hypotheses:

H2a: fiscal and tax policy support positively moderates the relationship between complementary knowledge coupling and firms' incremental innovation.

$\mathrm{H} 2 \mathrm{~b}$ : fiscal and tax policy support negatively moderates the relationship between substitutable knowledge coupling and firms' incremental innovation.

A large number of scholars have analyzed the positive effects of innovation environment on the reorganization of knowledge elements to enhance innovation results. Firstly, a good innovation environment can guide enterprises to constantly update their knowledge base according to market demands. The improvement of laws and regulations and intellectual property rights system, on the basis of protecting the legitimate rights and interests of enterprises, can also stimulate the enthusiasm of enterprises for innovation, to maximize the utility of knowledge achievements transformation.

Previous research proposed that government's environmental support is not conducive to the growth of innovation due to the combination of heterogeneity knowledge resources. As the government's innovation and development targets often vary with enterprises' innovation goals, some financial economy and talent incentive policies of the government can only drive some basic and common technology or industry development of firms and they do not help in stimulating firm searching and combining large amounts of heterogeneous knowledge elements to conduct cross-border knowledge searching activities. Therefore, this research proposes the following hypotheses:

$\mathrm{H} 2 \mathrm{c}$ : innovation environment support positively moderates the relationship between substitutable knowledge coupling and firms' incremental innovation.

$\mathrm{H} 2 \mathrm{~d}$ : innovation environment support negatively moderates the relationship between complementary knowledge coupling and firms' incremental innovation.

Based on the above, the research framework of this paper is shown in Figure 1.

\section{Research Methods}

In this study, questionnaire survey was used to collect data. We chose Chinese high-tech enterprises as the sample for empirical analysis. To ensure the validity of questionnaire items, all variables in this study were measured by mature scales.

3.1. Samples and Data Collection. In this study, questionnaire survey was used to collect data, and the samples were mainly from Hunan, Sichuan, Guangdong, and Liaoning provinces in China. Our research involves 6 high-tech industries, such as machinery manufacturing and electronic information technology. Questionnaires were distributed mainly through students, alumni, acquaintances, and other channels, and we employed human resources or administrative personnel of focus enterprises to collect data on the spot. This survey selected senior, middle, and low-level managers as well as some core employees (such as technical and market backbone) who have worked in the enterprises for more than three years and were familiar with the firms' products and market conditions as the survey objects. The data collection involved two stages: the first stage was the predictive test, which was mainly used to analyze the questionnaire items and factors. 100 questionnaires were sent out through the classroom of MBA and EMBA, and 95 valid questionnaires were obtained. The second stage was formal investigation, which was used to test theoretical hypotheses. 250 questionnaires were sent out and 208 were collected with a recovery rate of $86.6 \%$. Twenty-four incomplete and invalid questionnaires were eliminated, and a total of 279 valid questionnaires were recovered. Sample distribution is shown in Table 1.

3.2. Variables. Except for the control variables, all variables in this study were measured by the Likert 5-point scale.

The scale of knowledge coupling was adjusted according to Yayavaram and Ahuja [3], Ryoo and Kim [28], Kim et al. [29], and Yayavaram and Chen [4]. The final knowledge coupling scale contains two dimensions: complementary knowledge coupling and substitutable knowledge coupling, each containing five items.

The firms' incremental innovation measurement refers to Jansen [30] scale, which consists of 5 items.

The government support policies refer to the research results of Shu et al. [31]. After adjustment, the government support policies included fiscal and tax policies and innovative environment policies, consisting of 4 and 5 items, respectively.

In order to eliminate the potential interference factors, this study introduces three control variables, namely, firm age, firm size, and technological turbulence.

\section{Data Analysis and Results}

After data collection, we conducted some analysis by software SPSS 21.0 to verify the hypotheses proposed above.

4.1. Reliability and Validity Analysis. After data collection, validity analysis was performed for each construct. First, the fitting index of this model is as follows: $\chi^{2}=691.832$, $\mathrm{DF}=337, \quad \chi^{2} / \mathrm{DF}=2.053, \quad \mathrm{RMSEA}=0.056, \quad \mathrm{CFI}=0.929$, IFI $=0.935$, and TLI $=0.928$, which indicates that this model has a good fitting degree. Secondly, the exploratory factor analysis indicates that Cronbach $\alpha$ and comprehensive reliability coefficient (CR) of all constructs are greater than 0.8 , and thus the model has ideal internal consistency. Thirdly, the factor load of all items in this paper is greater than 0.7, and the average extraction variance (AVE) of each latent variable is greater than 0.5 , indicating that the model has 


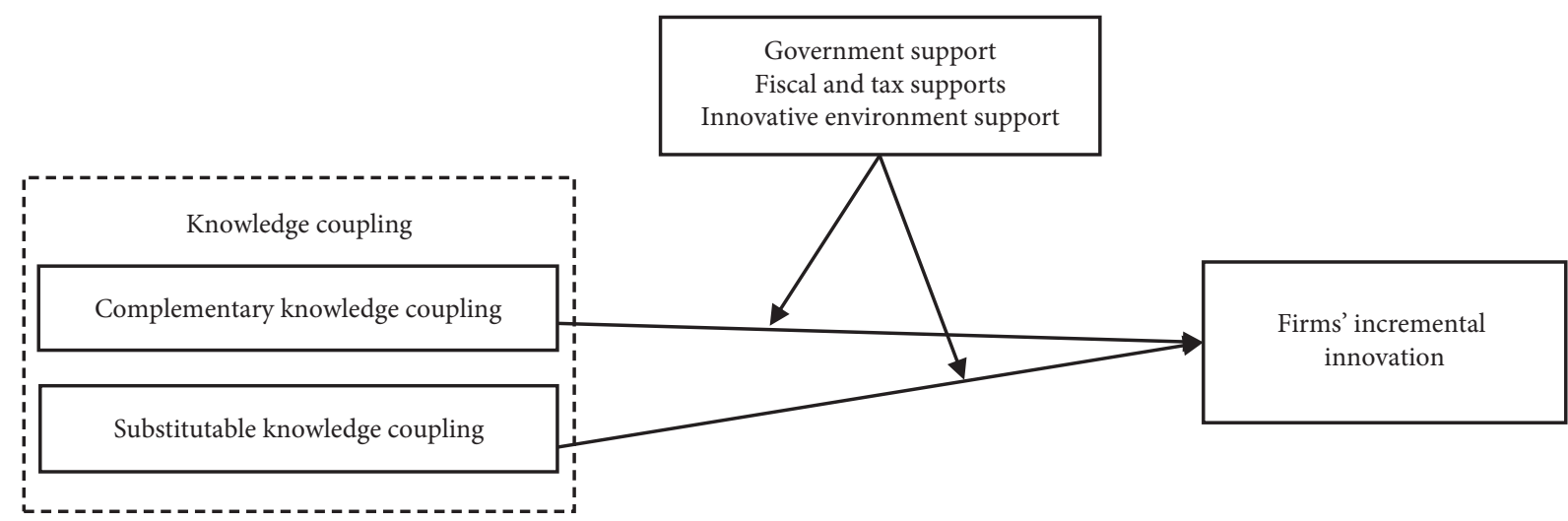

Figure 1: The conceptual model of this study.

TABLE 1: Distribution of sample features.

\begin{tabular}{|c|c|c|c|c|}
\hline Variable & Items & Percentage & Items & Percentage \\
\hline Gender & Male & 74.24 & Female & 26.76 \\
\hline \multirow{2}{*}{ Education } & $<$ Undergraduate & 6.51 & Undergraduate & 62.37 \\
\hline & $>$ Undergraduate & 31.12 & & \\
\hline \multirow{2}{*}{ Corporate property } & State-owned enterprises & 27.83 & Private enterprises & 28.91 \\
\hline & Foreign enterprises & 18.10 & Joint venture enterprises & 25.16 \\
\hline \multirow{2}{*}{ Firm age } & $<3$ years & 4.31 & $3-5$ years & 5.01 \\
\hline & $5-10$ years & 7.54 & $\geq 10$ years & 83.14 \\
\hline \multirow{2}{*}{ Firm size } & $<100$ employees & 3.87 & 100-499 employees & 5.91 \\
\hline & 500-1000 employees & 8.03 & $>1000$ employees & 82.19 \\
\hline \multirow{3}{*}{ Industry } & Machinery manufacturing & 22.45 & Automobile & 23.19 \\
\hline & Electronics and information technology & 20.63 & Software & 14.28 \\
\hline & Bioengineering and new medical technology & 8.92 & New energy and new materials & 10.53 \\
\hline
\end{tabular}

good cohesion validity. Finally, the square root of AVE of each variable in the model is greater than the correlation coefficient between this variable and other variables (see Table 2), so the measurement model has a high discriminant validity.

To avoid possible common method biases in data results, the Harman univariate analysis method was used for post hoc statistical analysis. Exploratory factor (no rotation) analysis was performed on all key variables involved in this paper, and it was found that none of the variables were loaded into a single coefficient, and none of the total coefficients accounted for most of the covariance of the dataset (the highest explanatory variance of the three variables accounted for $19.807 \%$ of the total interpretation of the variance). Therefore, the problem of common method deviation is not serious in this study.

4.2. Model Tests. This paper adopts hierarchical regression via SPSS 21.0 to verify the direct impact of knowledge coupling on firms' incremental innovation, as well as the moderating role of government support in this relationship.

4.2.1. Test of the Direct Effect of Knowledge Coupling on Firms' Incremental Innovation. Table 2 shows the results of descriptive statistics and correlation analysis. This paper adopts hierarchical regression via SPSS 21.0 to verify the direct impact of knowledge coupling on firms' incremental innovation. The regression analysis results are shown in Table 3. Model 1 is a benchmark model containing only control variables. Model 2 shows that the regression coefficient of complementary knowledge coupling is positive $(\beta=0.318$, $p<0.001$ ); according to the results of Model 3, the regression coefficients of complementary knowledge coupling and complementary knowledge coupling square are positive $(\beta=0.313, p<0.001)$ and negative $(\beta=-0.182, p<0.01)$, indicating an inverted U-shaped relationship between complementary knowledge coupling and firms' incremental innovation. Hypothesis H1a is supported. Similarly, Model 4 shows that the regression coefficient of substitutable knowledge coupling is positive $(\beta=0.287, p<0.001)$; according to the results of Model 5, the regression coefficient of substitutable knowledge coupling is positive after adding substitutable knowledge coupling square $(\beta=0.273, p<0.001)$, and the regression coefficient of substitutable knowledge coupling square is not significant, indicating a positive correlation between substitutable knowledge coupling and firms' incremental innovation. Therefore, H1b is supported.

To shed further light on the inverted U-shaped relationship, we also plot the effects of complementary knowledge coupling on firms' incremental innovation as illustrated in Figure 2 [32]. 
TABLE 2: Descriptive statistics and correlation analysis.

\begin{tabular}{|c|c|c|c|c|c|c|c|c|c|c|}
\hline & Mean & $\mathrm{SD}$ & FA & FS & TT & CKC & SKC & FTS & IES & II \\
\hline FA & 3.56 & 0.93 & - & & & & & & & \\
\hline FS & 3.38 & 1.05 & $0.54^{* *}$ & - & & & & & & \\
\hline TT & 3.58 & 0.79 & 0.08 & 0.12 & 0.71 & & & & & \\
\hline CKC & 3.54 & 0.70 & 0.14 & 0.07 & $0.48^{* *}$ & 0.74 & & & & \\
\hline SKC & 3.83 & 0.76 & -0.02 & 0.08 & $0.40^{* *}$ & $0.62^{* *}$ & 0.75 & & & \\
\hline FTS & 3.50 & 0.94 & 0.07 & $0.16^{*}$ & $0.55^{* *}$ & $0.50^{* *}$ & $0.38^{* *}$ & 0.78 & & \\
\hline IES & 3.56 & 0.89 & 0.00 & $0.23^{* *}$ & $0.60^{* *}$ & $0.53^{* *}$ & $0.43^{* *}$ & $0.79^{* *}$ & 0.76 & \\
\hline II & 3.91 & 0.70 & 0.10 & $0.12^{*}$ & $0.54^{* *}$ & $0.51^{* *}$ & $0.46^{* *}$ & $0.40^{* *}$ & $0.44^{* *}$ & 0.75 \\
\hline
\end{tabular}

Note. $N=279$; the diagonal in italics is the square root of the AVE; ${ }^{* *} P<0.01 ;{ }^{*} P<0.05$. FA $=$ firm age; FS $=$ firm size; TT $=$ technology turbulence; $\mathrm{CKC}=$ complementary knowledge coupling; $\mathrm{SKC}=$ substitutable knowledge coupling; FTS = finance and tax policy support; IES = innovation environmental support; II = incremental innovation.

TABLE 3: Test of direct effect of knowledge coupling on firms' incremental innovation.

\begin{tabular}{|c|c|c|c|c|c|}
\hline \multirow{2}{*}{ Variables } & \multicolumn{5}{|c|}{ Incremental innovation } \\
\hline & Model 1 & Model 2 & Model 3 & Model 4 & Model 5 \\
\hline \multicolumn{6}{|l|}{ Controls } \\
\hline Firm age & 0.010 & 0.099 & 0.106 & 0.116 & 0.115 \\
\hline Firm size & -0.006 & -0.008 & -0.004 & -0.022 & -0.016 \\
\hline Technology turbulence & $0.543^{* * *}$ & $0.391^{* * *}$ & $0.313^{* * *}$ & $0.430^{* * *}$ & $0.415^{* * *}$ \\
\hline \multicolumn{6}{|l|}{ Predictors } \\
\hline Complementary knowledge coupling & & $0.318^{* * *}$ & $0.82^{* *}$ & & \\
\hline Complementary knowledge coupling ${ }^{2}$ & & & $-0.143^{* *}$ & & \\
\hline Substitutable knowledge coupling & & & & $0.287^{* * *}$ & $0.273^{* * *}$ \\
\hline Substitutable knowledge coupling ${ }^{2}$ & & & & & -0.101 \\
\hline $\mathrm{F}$ & $40.125^{* * *}$ & $42.432^{* * *}$ & $35.616^{* * *}$ & $40.836^{* * *}$ & $34.417^{* * *}$ \\
\hline$R^{2}$ & 0.304 & 0.383 & 0.395 & 0.373 & 0.387 \\
\hline Adjusted $R^{2}$ & 0.297 & 0.373 & 0.384 & 0.364 & 0.375 \\
\hline
\end{tabular}

Note. ${ }^{* * *} P<0.001 ;{ }^{* *} P<0.01$.

4.2.2. Moderating Effect Test of Government Support Policies. This paper uses regression equation to verify the regulatory effect of government support policies. In order to avoid multicollinearity, all variables are normalized. In addition, the VIF values of each variable are less than 2 , indicating that the multicollinearity problem is not serious.

The regression analysis results are shown in Table 4. Model 1 is a benchmark model containing only control variables. After adding the interaction items of knowledge coupling and government support policies, the significant coefficient of Model 3 was improved and increased, and the interaction coefficient of complementary knowledge coupling with fiscal and taxation policies is $0.207(p<0.001)$; the interaction coefficient of substitutable knowledge coupling with fiscal and taxation policies is -0.353 $(p<0.001)$, indicating that the fiscal and taxation support positively moderates the relationship between complementary knowledge coupling and firms' incremental innovation, while the fiscal and taxation support negatively moderates the relationship substitutable knowledge coupling and firms' incremental innovation, and thus hypotheses $\mathrm{H} 2 \mathrm{a}$ and $\mathrm{H} 2 \mathrm{~b}$ are supported. Similarly, the interaction coefficient between complementary knowledge coupling and innovative environment support is -0.183 $(p<0.01)$, and the interaction coefficient between substitutable knowledge coupling and innovative environment is $0.329(p<0.001)$, indicating that innovative environment support negatively moderates the relationship between complementary knowledge coupling and firms' incremental innovation, while innovative environment support positively moderates the relationship between substitutable knowledge coupling and firms' incremental innovation, supporting $\mathrm{H} 2 \mathrm{c}$ and $\mathrm{H} 2 \mathrm{~d}$.

4.2.3. The Fitness between Government Support and Knowledge Coupling. By comparing the different moderating effects of different government support policies on the relationship between knowledge coupling types and firms' incremental innovation in Table 4, it can be concluded that enterprises implement complementary knowledge coupling strategy, and the government adopts fiscal and tax support policies, which is more conducive to their innovation results. When firms adopt substitutable knowledge coupling strategy, the government uses innovative environment policy better for promoting their incremental innovation. Therefore, on the premise of improving firms' incremental innovation, there is a matching relationship between government support policies and knowledge coupling strategies, as shown in Figure 3. 


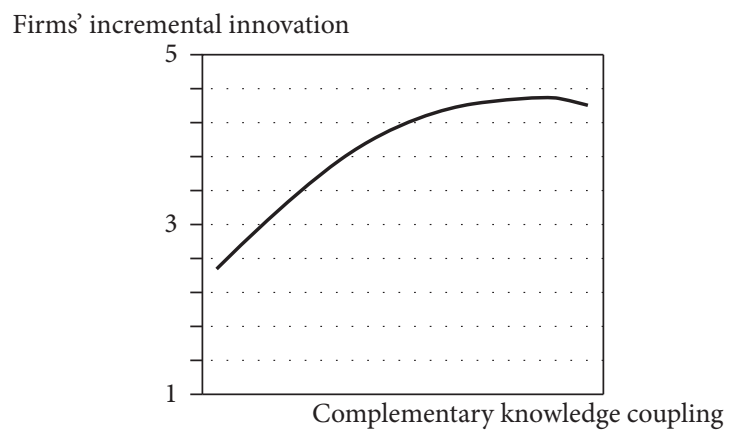

FIGURE 2: The U-shaped relationship between complementary knowledge coupling and firms' incremental innovation.

TABLE 4: Moderating effect test of government support policies.

\begin{tabular}{|c|c|c|c|}
\hline \multirow{2}{*}{ Variables } & \multicolumn{3}{|c|}{ Incremental innovation } \\
\hline & Model 1 & Model 2 & Model 3 \\
\hline \multicolumn{4}{|l|}{ Controls } \\
\hline Firm age & 0.010 & 0.108 & 0.106 \\
\hline Firm size & -0.006 & -0.023 & -0.004 \\
\hline Technology turbulence & $0.543^{* * *}$ & $0.335^{* * *}$ & $0.313^{* * *}$ \\
\hline \multicolumn{4}{|l|}{ Predictors } \\
\hline Complementary knowledge coupling & & $0.251^{* * *}$ & $0.197^{* * *}$ \\
\hline Substitutable knowledge coupling & & $0.217^{* * *}$ & $0.178^{* * *}$ \\
\hline Finance and tax policy support & & -0.002 & -0.010 \\
\hline Innovation environmental support & & 0.042 & 0.081 \\
\hline Complementary knowledge coupling ${ }^{*}$ finance and tax policy support & & & $0.207^{* * *}$ \\
\hline Substitutable knowledge coupling ${ }^{*}$ finance and tax policy support & & & $-0.353^{* * *}$ \\
\hline Complementary knowledge coupling * innovation environmental support & & & $-0.183^{* *}$ \\
\hline Substitutable knowledge coupling ${ }^{*}$ innovation environmental support & & & $0.329^{* * *}$ \\
\hline F & $40.125^{* * *}$ & $25.966^{* * *}$ & $18.143^{* * *}$ \\
\hline$R^{2}$ & 0.304 & 0.401 & 0.428 \\
\hline Adjusted $R^{2}$ & 0.297 & 0.386 & 0.404 \\
\hline
\end{tabular}

Note. ${ }^{* * *} P<0.001 ;{ }^{* *} P<0.01$.

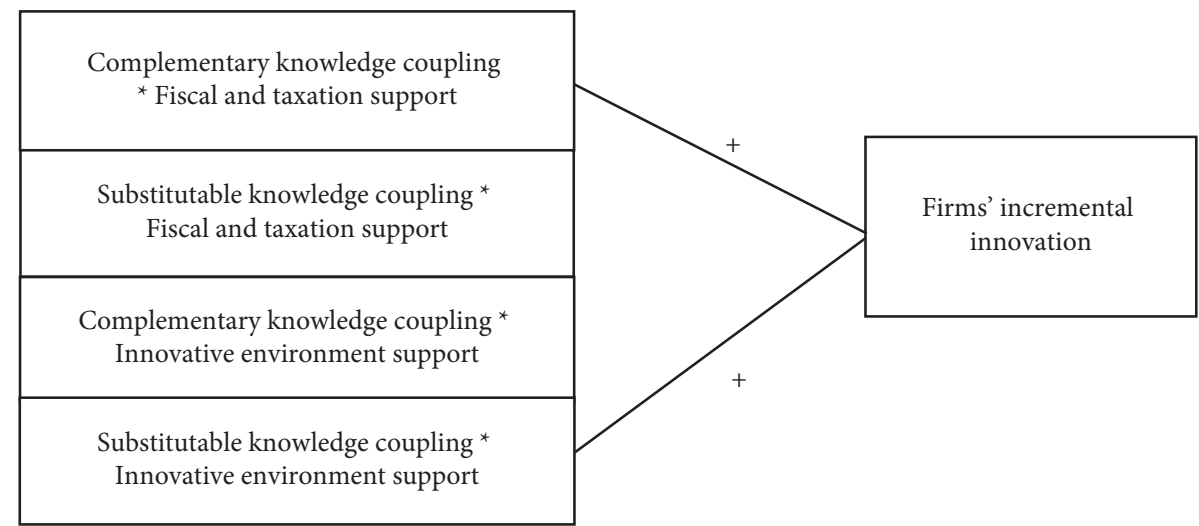

FiguRE 3: The fitness model of government support and knowledge coupling.

\section{Conclusions}

In this part, we aim to state the research results of this paper as well as management implications for future study.

5.1. Conclusions and Discussion. From the perspective of resource arrangement, this paper focuses on different influences of knowledge coupling on firms' incremental innovation and the moderating effects of government support policies in this relationship. Based on the empirical analysis results of 279 questionnaires from high-technology firms, the following conclusions are drawn:

Firstly, there is an inverted U-shaped relationship between complementary knowledge coupling and firms' incremental innovation, while substitutable knowledge coupling is positively related to firms' incremental 
innovation. The results show that when the coupling degree of knowledge elements in different domain is low, it is in favor of firms' incremental innovation, but when the coupling degree of heterogeneous knowledge elements is elevated to a certain degree, it is not conducive to firms' incremental innovation of enterprises. This conclusion extends the view that the process of knowledge element reorganization may have a negative impact on enterprises' innovation results in a specific industry or environment [5], indicating that the combination of knowledge elements in different fields does not necessarily lead to a higher level of innovation. This may be because the searching costs of knowledge elements from different knowledge domains have a certain degree of "crowding-out effect" on firms' independent research and development costs. These analysis results enrich the knowledge management and resource orchestration theory. The empirical results also show that the reorganization of knowledge elements in the same or familiar domain can effectively enhance enterprises' incremental innovation. This may due to the reorganization of knowledge elements in the same or familiar technical fields which is helpful to update firms' knowledge base and eliminate their old knowledge to avoid falling into the "familiarity trap" [8]. The research results indicate that the coupling types of knowledge elements have a differentiation effect on firms' incremental innovation.

Secondly, different government support policies have different moderating effects on the relationship between knowledge coupling and firms' incremental innovation. Prior literature has paid little attention on how different government support policies affect firms' innovation outcomes [11]. Thus, the impact of government support on firm's innovation needs to be clarified by conducting more studies. Our empirical analysis results show that fiscal and tax support positively moderates the relationship between complementary knowledge coupling and firm's incremental innovation, while it negatively moderates relationship between substitutable knowledge coupling and firm's incremental innovation. Similarly, our research results demonstrate that innovative environment support plays a negative moderating effect on the relationship between complementary knowledge coupling and firms' incremental innovation, while it plays a positive moderating role on the relationship between substitutable knowledge coupling and firms' incremental innovation. Therefore, we can conclude that when firms implement complementary knowledge coupling strategy, the government's fiscal and tax support policies are more conducive to promoting incremental innovation of enterprises. When firms adopt substitutable knowledge coupling strategy, the government adopts innovative environment policy for improving firms' incremental innovation.

Overall, this paper puts forward a new view that the matching of government support policy and knowledge coupling strategy is more conducive to firms' incremental innovation. There is still some controversy about whether and how government support influences enterprises innovation. This study goes beyond the extant literature by examining the different effects of various types of government support on firms' innovation. Our results further show that the synergistic effects between government policies and enterprises innovation can promote better incremental innovation, which provide an understanding of government support in the cross study of knowledge management and firm innovation.

5.2. Management Implications. The research results have the following implications for firms' knowledge searching and innovation practice.

First of all, enterprises should take into account the interaction effects of different knowledge elements to achieve the combination of old and new knowledge and enterprises' innovation. Under the background of digital economy, enterprises increasingly need to acquire heterogeneous knowledge resources across boundaries to meet their innovation goals. On the one hand, firms can make full use of the vertical connections in the innovation network, to search and couple the complementary knowledge elements to improve existing products or services more effectively. On the other hand, organizations should pay close attention to the product dynamics of cooperative partners in the cooperation network, so as to facilitate the acquisition and combination of knowledge elements in similar technical fields, to enhance the efficiency of internal operation and technology research activities.

Secondly, managers should make full use of the fitness effects between government support policies and knowledge coupling types in firms' incremental innovation. In other words, managers can choose appropriate government support policies according to their knowledge coupling strategy to achieve innovation goals. When enterprises aim to carry out complementary knowledge coupling strategy, they can use fiscal and tax policies to relieve the internal financial pressure. When enterprises focus on reorganizing knowledge elements in familiar fields, the synergistic effect of innovative environmental policy can be exerted to promote internal knowledge base renewal and operational efficiency improvement.

5.3. Limitations and Future Study. Similar to most previous studies, this study has some limitations that provide directions for future research. First of all, the important role of knowledge coupling on firm innovation has been widely recognized by prior research. Future study can try to explore the influence of knowledge coupling on firms' entry into new markets. The ability of enterprises to utilize heterogeneous knowledge elements can, to some extent, provide new opportunities for them to expand new markets or businesses [17]. Therefore, it can be explored whether the interaction of knowledge elements in different technical fields can make enterprises profitable in the process of entering new markets. Secondly, although the problem of common variance is not serious in this paper, it can be considered to fill in different parts of the questionnaire by different people who are familiar with the enterprise in future research, so as to ensure the objectivity of research data. 


\section{Data Availability}

All data generated or analyzed during this study are included within this article.

\section{Conflicts of Interest}

The authors declare that they have no conflicts of interest.

\section{Acknowledgments}

This study was supported by the Youth Project of Guangdong Provincial Philosophy and Social Science Plan (grant no. GD20YGL06) and the Youth Project of Regional Joint Fund Project of Guangdong Provincial Basic and Applied Basic Research Fund (grant no. 2020A1515110775).

\section{References}

[1] P. Shapira, J. Youtie, K. Yogeesvaran, and Z. Jaafar, "Knowledge economy measurement: methods, results and insights from the Malaysian knowledge content study," Research Policy, vol. 35, no. 10, pp. 1522-1537, 2006.

[2] R. M. Grant, "Toward a knowledge-based theory of the firm," Strategic Management Journal, vol. 17, no. S2, pp. 109-122, 1996.

[3] S. Yayavaram and G. Ahuja, "Decomposability in knowledge structures and its impact on the usefulness of inventions and knowledge-base malleability," Administrative Science Quarterly, vol. 53, no. 2, pp. 333-362, 2008.

[4] H. Chen, Y. Yao, and H. Zhou, "How does knowledge coupling affect exploratory and exploitative innovation? The chained mediation role of organisational memory and knowledge creation," Technology Analysis \& Strategic Management, vol. 33, no. 6, pp. 713-727, 2020.

[5] S. Yayavaram and W.-R. Chen, "Changes in firm knowledge couplings and firm innovation performance: the moderating role of technological complexity," Strategic Management Journal, vol. 36, no. 3, pp. 377-396, 2015.

[6] D. G. Sirmon, M. A. Hitt, R. D. Ireland, and B. A. Gilbert, "Resource orchestration to create competitive advantage," Journal of Management, vol. 37, no. 5, pp. 1390-1412, 2011.

[7] C. M. Carnes, F. Chirico, M. A. Hitt, D. W. Huh, and V. Pisano, "Resource orchestration for innovation: structuring and bundling resources in growth- and maturity-stage firms," Long Range Planning, vol. 50, no. 4, pp. 472-486, 2017.

[8] F. Yu, Z. Hu, L. Dong, and Z. Chen, "Research on the influence mechanism of knowledge coupling on enterprise breakthrough innovation," Nankai Management Review (in Chinese), vol. 36, no. 12, pp. 2292-2304, 2018.

[9] A. C. Chu, G. Cozzi, and Y. Furukawa, "Effects of economic development in China on skill-biased technical change in the US," Review of Economic Dynamics, vol. 18, no. 2, pp. 227-242, 2015.

[10] C. Zhang, P. Sun, and J. Xie, "Does the position of the production chain affect the choice of innovation mode: based on the theory and empirical research from a micro perspective," Management World, no. 1, pp. 45-59, 2020.

[11] H. T. T. Nguyen, H. V. Van, H. V. Van, F. Bartolacci, and T. Q. Tran, "The impact of government support on firm performance in Vietnam: new evidence from a dynamic approach," Asian Academy of Management Journal, vol. 23, no. 2, pp. 101-123, 2018.
[12] M. Tripsas and G. Gavetti, "Capabilities, cognition, and inertia: evidence from digital imaging," Strategic Management Journal, vol. 21, no. 10-11, pp. 1147-1161, 2000.

[13] S. A. Zahra and G. George, "Absorptive capacity: a review, reconceptualization, and extension," Academy of Management Review, vol. 27, no. 2, pp. 185-203, 2002.

[14] P. S. Barr, J. L. Stimpert, and A. S. Huff, "Cognitive change, strategic action, and organizational renewal," Strategic Management Journal, vol. 13, no. S1, pp. 15-36, 1992.

[15] K. D. Miller, "Knowledge inventories and managerial myopia," Strategic Management Journal, vol. 23, no. 8, pp. 689-706, 2002.

[16] M. P. Knudsen, "The relative importance of interfirm relationships and knowledge transfer for new product development success," Journal of Product Innovation Management, vol. 24, no. 2, pp. 117-138, 2007.

[17] L. Dibiaggio, M. Nasiriyar, and L. Nesta, "Substitutability and complementarity of technological knowledge and the inventive performance of semiconductor companies," Research Policy, vol. 43, no. 9, pp. 1582-1593, 2014.

[18] D. J. Teece, "Profiting from technological innovation: implications for integration, collaboration, licensing and public policy,” Research Policy, vol. 15, no. 6, pp. 285-305, 1986.

[19] F. T. Rothaermel, "Incumbent's advantage through exploiting complementary assets via interfirm cooperation," Strategic Management Journal, vol. 22, no. 6-7, pp. 687-699, 2001.

[20] A. Rindfleisch and C. Moorman, "The acquisition and utilization of information in new product alliances: a strength-ofties perspective," Journal of Marketing, vol. 65, no. 2, pp. 1-18, 2001.

[21] E. Danneels, "The dynamics of product innovation and firm competences," Strategic Management Journal, vol. 23, no. 12, pp. 1095-1121, 2002.

[22] A. Nerkar, "Old is gold? The value of temporal exploration in the creation of new knowledge," Management Science, vol. 49, no. 2, pp. 211-229, 2003.

[23] H. Zhou, K. Yuan Wang, Y. Yao, and K.-P. Huang, "The moderating role of knowledge structure in the open innovation effect," Management Decision, vol. 57, no. 9, pp. 2223-2238, 2019.

[24] F. Yu, M. Liu, L. Wang, and L. Li, “The influence mechanism of knowledge coupling on enterprise green innovation: the moderating effect of redundant resources," Nankai Management Review (in Chinese), vol. 22, no. 3, pp. 54-65+76, 2019.

[25] J. Jiang, "The performance of public policy on enterprise innovation support: a comparative analysis based on direct subsidies and tax incentives," Scientific Research Management (in Chinese), vol. 32, no. 4, pp. 1-8, 2011.

[26] K.-N. Kang and H. Park, "Influence of government R\&D support and inter-firm collaborations on innovation in Korean biotechnology SMEs," Technovation, vol. 32, no. 1, pp. 68-78, 2012.

[27] R. Kleer, "Government R\&D subsidies as a signal for private investors," Research Policy, vol. 39, no. 10, pp. 1361-1374, 2010.

[28] S. Y. Ryoo and K. K. Kim, "The impact of knowledge complementarities on supply chain performance through knowledge exchange," Expert Systems with Applications, vol. 42, no. 6, pp. 3029-3040, 2015.

[29] K. K. Kim, N. S. Umanath, J. Y. Kim, F. Ahrens, and B. Kim, "Knowledge complementarity and knowledge exchange in supply channel relationships," International Journal of Information Management, vol. 32, no. 1, pp. 35-49, 2012. 
[30] J. J. P. Jansen, F. A. J. Van Den Bosch, and H. W. Volberda, "Exploratory innovation, exploitative innovation, and performance: effects of organizational antecedents and environmental moderators," Management Science, vol. 52, no. 11, pp. 1661-1674, 2006.

[31] C. Shu, K. Z. Zhou, Y. Xiao, and S. Gao, "How green management influences product innovation in China: the role of institutional benefits," Journal of Business Ethics, vol. 133, no. 3, pp. 471-485, 2016.

[32] L. Toothaker, "Multiple regression: testing and interpreting interactions," Journal of the Operational Research Society volume, no. 45, pp. 119-120, 1994. 